\title{
PENURUNAN KAPASITAS MEMORI KERJA PADA RESIDEN PEDIATRI YANG KURANG TIDUR
}

\author{
Herwanto $^{1}$, Adrian Umboh ${ }^{2}$ \\ ${ }^{1}$ Fakultas Kedokteran, Universitas Tarumanagara, Jakarta \\ ${ }^{2}$ Departemen Ilmu Kesehatan Anak, Fakultas Kedokteran, Universitas Sam Ratulangi \\ Prof Dr R. D. Rumah Sakit Kandou, Manado
}

\begin{abstract}
ABSTRAK
Beberapa penelitian menjelaskan terjadi kesalahan medis seperti kesalahan dokumentasi dan efek yang tidak diinginkan terkait dengan kurang tidur selama pendidikan spesialis. Telah ditemukan bukti penurunan waktu tidur selama bertugas yang akan mempengaruhi suasana hati, hubungan yang terkait stres dan kinerja. Kapasitas memori kerja adalah kemampuan untuk mempertahankan dan memanipulasi informasi atau masukan sensorik untuk melakukan banyak tugas dan kombinasi perhatian, konsentrasi dan memori jangka pendek. Untuk mengukur efek dari tugas jaga malam pada kapasitas memori kerja residen pediatri. Antara Januari dan Februari 2014 residen menyelesaikan pengukuran kapasitas memori kerja dari Wechsler Adult Intelligence Scale saat tidak tugas jaga malam maupun setelah tugas jaga malam dan pengukuran tingkat mengantuk di siang hari menggunakan Epsworth sleepiness scale. Tujuh puluh satu residen menyelesaikan studi dengan hasil adanya hubungan yang signifikan antara skala kantuk epsworth saat tidak jaga dengan saat setelah jaga (r: 0.303, p: 0,005). Waktu tidur rerata saat jaga malam 2,98 jam, sedangkan tidur per malam untuk residen yang tidak bertugas jaga malam 6,55 jam. Didapatkan hubungan yang signifikan terkait penurunan kapasitas memori kerja pada residen setelah tugas jaga malam ( $r: 0.776, p<0,001)$. Tugas jaga malam menurunkan waktu tidur dan mempengaruhi kapasitas memori kerja. Penurunan kapasitas memori kerja dapat menjelaskan adanya suatu gangguan pengambilan keputusan selama terjadi kekurangan tidur.
\end{abstract}

Kata kunci: Kurang tidur, kapasitas memori kerja, pendidikan residen.

\section{PENDAhULUAN}

Program pendidikan dokter spesialis seringkali menimbulkan stres pada kehidupan profesional seorang residen. Residen diharapkan mampu memenuhi tuntutan klinis, akademis, fisis, dan sosial, sementara bekerja hingga 80 jam per minggu. Berdasarkan Undang - Undang Republik Indonesia No. 20 Tahun 2013 tentang pendidikan Kedokteran dikatakan pada pasal 31 bahwa setiap peserta pendidikan kedokteran berhak memperoleh waktu istirahat sesuai dengan waktu yang telah ditentukan. Pada studi oleh West dkk didapatkan hasil $47 \%$ residen ilmu penyakit dalam dilaporkan pernah melakukan suatu kesalahan serius selama masa pendidikan yang berhubungan dengan tingkat stress, penelitian tersebut juga mengatakan residen pada berbagai tingkatan dilaporkan minimal pernah melakukan satu kesalahan medis selama masa studi yang dijalani.

Sebuah laporan dari Institute of Medicine pada tahun 1999 memperkirakan bahwa sekitar 100.000 orang meninggal di rumah sakit setiap tahun karena kesalahan medis yang sebenarnya dapat dicegah, 60\% - 80\% kesalahan tersebut disebabkan oleh kelelahan. Suatu penelitian eksperimental oleh Lambergyang membiarkan subyek penelitiannya tidak tertidur selama 90 jam. Pada subyek ini ditemukan penurunan ketajaman sensoris, reaksi, kecepatan motorik dan memori dan dikatakan juga bahwa gangguan tidur merusak fungsi kognitif yang ditandai oleh penurunan perhatian, kewaspadaan dan daya ingat akibat kerusakan korteks prefrontal yang memperantarai indra atensi dan emosi sehingga memerlukan penanganan yang adekuat.

Working Memory Capacity (WMC) adalah kemampuan untuk mempertahankan dan memanipulasi informasi atau masukan sensorik untuk melakukan banyak tugas dan merupakan kombinasi dari perhatian, konsentrasi, dan memori jangka pendek.Tujuan penelitian ini 
dilakukan adalah untuk mengukur efek dari tugas jaga malam terhadap kapasitas memori kerja residen pediatrik selama menjalani pendidikan dokter spesialis anak.

\section{METODE PENELITIAN}

Studi potong-lintang, deskriptif-analitik, dilakukan di Departemen Ilmu Kesehatan Anak Fakultas Kedokteran Universitas Sam Ratulangi pada periode Januari - Februari 2014. Teknik pengambilan sampel secara random sampling terhadap residen yang masih terdaftar dalam Program Pendidikan Dokter Spesialis Ilmu Kesehatan Anak (PPDS IKA) pada kurun waktu penelitian. Kuesioner yang dibagikan ke seluruh residen berisi data dasar PPDS seperti jenis kelamin, usia, tahap pendidikan. Residen di bagikan kuesioner Epsworth sleepiness scale untuk diisi setelah bertugas jaga malam dan saat tidak ada tugas jaga malam untuk melihat tingkat mengantuk di siang hari pada seorang residen. WMC diukur menggunakan working memory index dari Wechsler Adult Intelligence Scale saat setelah bertugas jaga malam maupun saat tidak ada tugas jaga malam sebelumnya. Semua data yang terkumpul di analisis.

\section{HASIL DAN PEMBAHASAN}

Terdapat 71 peserta PPDS IKA pada penelitian yang terdiri dari 37 (52\%) PPDS laki lakidan 34 (48\%) PPDS wanita. Tingkat pendidikan peserta penelitian yaitu $31 \%$ pada tahap senior, $39 \%$ pada tahap madya dan $30 \%$ pada tahap junior. Saat tugas jaga malam tim jaga malam dibagi menjadi 4 ruangan jaga, yaitu ruangan bangsal, ruangan perawatan intensif anak, ruangan perawatan intensif bayi baru lahir dan instalasi gawat darurat anak. Lama waktu tidur yang dilaporkan dari para peserta didik saat sedang tidak bertugas jaga malam yaitu rata -rata 6,5 jam dengan median nya 6 jam, rentang waktu tidur para peserta didik saat tidak tugas jaga malam yaitu 5 jam -8 jam. Lama waktu tidur yang dilaporkan dari para peserta didik saat sedang bertugas jaga malam yaitu rata -rata 2,98 jam dengan mediannya 3 jam, rentang waktu tidur para peserta didik saat tugas jaga malam yaitu 1 jam -4 jam.

Penilaian mengantuk di siang hari menggunakan kuesioner Epsworth sleepiness scale yang terdiri dari 8 pertanyaan yang harus diberikan penilaian $0-3$, dengan nilai maksimal yang bisa didapat adalah 24. Interpretasi dari nilai total yang didapatkan dari kuesioner tersebut di artikan normal bila nilai dalam rentang $0-10$, dalam tingkat mengantuk yang ringan sampai sedang bila rentang nilai $11-15$, serta kondisi mengantuk berat jika nilai total $16-24$. PPDS diminta untuk mengisi dengan jujur kuesioner yang dibagikan tersebut sesuai dengan tingkat mengantuk yang dialami peserta pada saat itu juga, baik kondisi setelah jaga malam maupun kondisi tidak jaga malam hari sebelumnya. Didapatkan hasil rata rata nilai Epsworth sleepiness scale setelah jaga malam yaitu 14,5 dengan rentang nilai 5 - 23 poin total dari nilai Epsworth sleepiness scale, dan nilai mediannya 15. Sedangkan hasil rata rata nilai Epsworth sleepiness scale tanpa jaga malam yaitu 6 dengan rentang nilai 1 - 15 poin total dari nilai Epsworth sleepiness scale, dan nilai mediannya 5.

Working memory capacity dari Wechsler Adult Intelligence Scale digunakan untuk menilai kapasitas memori kerja dari peserta program dokter spesialis, metode menggunakan suatu metode ukur deret angka, para peserta didik diminta untuk menghafalkan dan mengulang deret angka yang disebutkan saat kondisi setelah jaga malam maupun kondisi tanpa jaga malam sebelumnya. PenilaianWechsler Adult Intelligence Scaleyaitu 4-6 adalah batas bawah daripada skala Wechsler, 7-8 nilai di bawah rata - rata, 9-11 nilai rata-rata, 12-13 nilai di atas rata-rata, 14-16 nilai superior dan > 16 nilai sangat superior dalam hal kapasitas memori kerja dari peserta yang mengikuti penelitian. Hasil yang didapatkan setelah dilakukan pengukuran yaitu nilai ratarata dari kapasitas memori kerja setelah jaga malam yaitu 12,9 , dengan nilai median 13 , dan 
rentang nilai yang didapatkan $8-16$. Hasil yang didapatkan setelah dilakukan pengukuran saat tidak dalam kondisi paska jaga malam, nilai rata - rata dari kapasitas memori kerja yaitu 14,08, dengan nilai median 14, dan rentang nilai yang didapatkan $11-17$.

Tabel 1. Data Demografi Subjek penelitian

\begin{tabular}{ll}
\hline DATA DEMOGRAFI & \\
\hline JENIS KELAMIN $\mathfrak{n}(\%)$ & \\
Laki laki & $37(52 \%)$ \\
Perempuan & $34(48 \%)$ \\
\hline TINGKAT PENDIDIKAN, n (\%) & \\
Senior & $22(31 \%)$ \\
Madya & $28(39 \%)$ \\
Junior & $21(30 \%)$ \\
\hline MEAN SLEEP TIME (hour) & \\
Tidak tugas jaga & 6,55 \\
Tugas jaga & 2,98 \\
\hline MEAN EPSWORTH & \\
Tidak tugas jaga & 6 \\
Tugas jaga & 14,5 \\
\hline MEAN WORKING & MEMORY \\
\multicolumn{1}{c}{ INDEX } & \\
Tidak tugas jaga & 14,08 \\
Tugas jaga & 12,94 \\
\hline
\end{tabular}

Tabel 2. Korelasi Kapasitas memori kerja dengan tingkat mengantuk Subjek penelitian

\section{Working memory index Epsworth Jaga malam Pasca jaga malam}

\begin{tabular}{llll}
\hline Effect & P Value & Effect & P Value \\
\hline
\end{tabular}

Working Memory indeks

Tidak jaga malam

Setelah dilakukan analisis statistik didapatkan adanya hubungan bermakna antara nilai kapasitas memori paska jaga malam dan nilai kapasitas memori tanpa jaga malam sebelumnya, dengan 
nilai $r=0,776$ dan $\mathrm{p}<0,001$. Adapun hasil pengujian secara statistic dari Epsworth sleepiness scale didapatkan adanya hubungan yang bermakna denga nilai $r=0,303$ dan $p<0,005$. Hasil penelitian ini menunjukkan bahwa terdapat telah terjadi suatu kelelahan yang terjadi pada PPDS paska jaga malam, dan tingkat kelelahan itu ditunjukkan dengan penilaian mengantuk disiang hari yang cukup tinggi. Terjadinya penurunan kapasitas memori kerja juga terjadi pasca jaga malam, yang dapat berakibat pada berkurang nya konsentrasi dan penilain keputusan medis yang baik.

\section{Pembahasan}

Kematian adalah sesuatu yang tidak bisa dihindari oleh manusia, namun demikian kematian juga merupakan salah satu indikator mutu pelayanan kesehatan yang penting. World Health Organization (WHO) menyatakan bahwa dari tahun 2005-2010 diperkirakan terdapat 850 kematian per 100.000 penduduk yang terjadi setiap tahunnya. Tingginya angka kematian di RS merupakan pertanda kemungkinan adanya masalah mutu pelayanan yang memerlukan tindakan perbaikan, hal ini ditunjukan antara lain dalam buku "to err is human" dari IOM maupun dari penelitian yang dilakukan oleh Hayward yang mengungkapkan bahwa kurang lebih 22,7\% dari kematian yang terjadi di RS sebenarnya dapat dihindarkan dengan perawatan optimal.

Dalam upaya menurunkan kemungkinan kesalahan medis yang terjadi terkait keselamatan pasien, dan untuk meningkatkan kesehatan residen agar terciptanya pendidikan residen yang lebih baik, Dewan Akreditasi Sarjana Pendidikan Kedokteran (ACGME) menetapkan persyaratan jam kerja pada residen menjadi kurang dari 80 jam per minggu, selain itu residen juga dilarang untuk mengambil tugas lembur sampai 30 jam atau lebih dan diharuskan untuk beristirahat 10 jam di tiap jeda antara tiap shift kerja. Pada tahun 2008, ACGME memperluas batasan dari jam kerja residen. Suatu studi terbaru melaporkan bahwa dengan pembatasan shift kerja dapat mengurangi risiko kesalahan medis dan mengurangi risiko kecelakaan. Tingkat dan mutu pelayanan mupun pendidikan pada seorang residen setelah bertugas dengan sangat berat (90 jam kerja per minggu dan tugas jaga malam setiap $4-5$ hari) didapatkan sama dan bahkan lebih buruk efeknya dengan kadar alkohol di dalam darah sebesar 0,04\% - 0,05\%.

Kurang tidur pada para residen telah ditemukan akan mempengaruhi suasana hati, hubungan interpersonal dengan residen lainnya, dan kinerja pada suatu simulasi. Mekanisme yang bertanggung jawab pada efek kurang tidur terhadap kinerja residen belum dieksplorasi secara mendalam. Penelitian sebelumnya telah mendokumentasikan kesalahan dan kejadian buruk yang terkait dengan kurang tidur pada residen. Penelitian ini mengeksplorasi perubahan dalam kapasitas memori kerja (WMC) pada residen yang kurang tidur sebagai mekanisme potensial yang mengarah ke kesalahan medis yang dapat terjadi dan efek samping lainnya yang tidak diinginkan.

Suatu penelitian menyimpulkan bahwa gangguan tidur yang dapat berupa kurangnya jumlah tidur atau waktu istirahat memiliki kaitan erat dengan kejadian ansietas, stress psikososial, dan gangguan afek. Dampak akibat gangguan tidur pada aspek mood, meliputi iritabilitas, mood yang berubah-ubah, dan kendali emosi yang buruk. Dampak pada fungsi kognitif meliputi atensi dan konsentrasi yang berkurang, waktu reaksi yang melambat, kewaspadaan yang berkurang, penurunan fungsi eksekutif (pengambilan keputusan, penyelesaian masalah), gangguan pembelajaran, dan prestasi belajar yang buruk. Sedangkan dampak gangguan tidur pada aspek perilaku meliputi hiperaktifitas, ketidakpatuhan, perilaku membangkang, kendali impuls yang buruk, peningkatan keinginan untuk mengambil risiko. Gangguan tidur juga dapat berdampak pada kehidupan berkeluarga, seperti efek negatif pada orang tua, stress keluarga, gangguan 
dalam pernikahan, serta masalah sosial lainnya. Gangguan pola tidur berupa pola tidur yang berlebihan dapat menimbulkan efek negatif pada performa di sekolah, fungsi kognitif, dan mood sehingga dapat menimbulkan konsekuensi serius lainnya seperti peningkatan angka kejadian kecelakaan kendaraan bermotor. Gangguan tidur sering kali diikuti dengan berbagai penyakit somatik, psikiatrik dan neurologis. Tidur yang buruk memiliki dampak negatif terhadap mood dan perilaku, gangguan tidur laten pada beberapa kasus dapat bermanifestasi sebagai gejala psikiatrik. Efek kurang tidur di antaranya penurunaan ketajaman sensoris, reaksi, kecepatan motorik dan memori. Kurangnya tidur terutama mempengaruhi fungsi korteks serebral. Perubahan hormonal yang menyerupai pertambahan usia dapat merupakan akibat dari kurang tidur. Kurang tidur juga dapat mempengaruhi sistem kardiovaskular dan tekanan darah.Gangguan tidur pada anak dengan berbagai gejala psikiatri antara lain depresi dan masalah perilaku.

Kapasitas Memori kerja adalah suatu fungsi kognitif yang memungkinkan individu untuk menyimpan informasi dalam pikiran, sementara pada saat yang sama memanipulasi informasi yang sama atau lainnya. Sebagai contoh, multi-tasking membutuhkan memori kerja karena seseorang harus melakukan berbagai kegiatan secara bersamaan. Demikian juga, mengalikan dua angka besar di kepala Anda memerlukan penggunaan memori kerja. Akibatnya, kapasitas memori kerja umumnya diukur dengan menentukan berapa banyak item seseorang bisa mengingat secara bersamaan untuk periode waktu yang singkat. Seseorang yang bisa mengingat semua 10 digit nomor telepon dan mengulanginya kembali memiliki kapasitas memori kerja lebih besar daripada seseorang yang hanya bisa mengingat empat. Ketika bekerja kapasitas memori sering dapat dinilai dengan menggunakan latihan sederhana yang sangat penting untuk akademik, profesional, dan kesejahteraan sosial. Terdapat berbagai tes untuk mengukur kapasitas memori kerja. Beberapa ukuran memori kerja dilakukan secara visual, dimana individu mengingat informasi visual, yang lain mengukur pendengaran memori kerja yaitu kemampuan untuk mengingat informasi pendengaran. Pada penelitian ini digunakan secara pendengaran, para peserta penelitian diminta untuk mendengar angka - angka yang disebutkan kemudian diminta untuk mengulanginya kembali, dan dinilai seberapa banyak kapasitas memori dari angka tersebut yang dapat diulang kembali dari residen tersebut.

Kapasitas memori kerja merupakan penanda baik untuk mekanisme penilaian untuk melihat adanya gangguan yang dapat terjadi pada pengambilan keputusan karena tugas dari seorang residen yang sifatnya, kompleks; residen juga diminta untuk secara bersamaan mengasimilasi, memprioritaskan, dan bertindak atas berbagai macam sumber informasi dalam suatu tugas dan pengaturan stres. Hal ini sangat penting karena tugas jaga malam dan kesalahan pengambilan keputusan medis paska jaga telah dilaporkan meningkat. Meskipun hasil penelitian ini menunjukkan suatu hubungan tugas jaga malam dengan pengurangan kapasitas memori pada residen, suatu kekurangan jumlah tidur juga bukan merupakan sepenuhnya suatu hal yang bisa memprediksi tingkat kesalahan dari seorang residen. Kesimpulannya, residen mengalami penurunan jumlah tidur saat tugas jaga malam, dan tugas jaga malam itu memengaruhi kapasitas memori kerja dari orang tersebut sehingga tingkat kesalahan medis yang dapat terjadi dapat lebih besar. Tingkat mengantuk di siang hari juga meningkat seiiring dengan paska jaga malam.

\section{REFERENSI}


Arnedt JT, Owens J, Crouch M, Stahl J, Carskadon M. Neurobehavioral performance of residents after heavy night call vs after alcohol ingestion. JAMA. 2005;294:1025-33.

Barger LK, Cade BE, Ayas NT. Extended work shifts and the risk of motor vehicle crashes among interns. N Engl J Med. 2005;352:125-34.

Budson AE, Price BH. Memory dysfunction. N Engl J Med. 2005; 352(7):692-9.

Cappuccio FP, Bakewell A, Taggart FM. Implementing a 48-hour EWDT-compliant rota (rotation) for junior doctors in the UK does not compromise patient's safety: assessorblind pilot comparison. QJM.2009;102:271-82.

Colom R, Rebollo I, Palacios A, Juan-Espinosa M, Kyllonen PC. Working memory is (almost) perfectly predicted by g. Intelligence.2004;32:277-296.

Fletcher KE, Underwood W, Davis SQ, Mangrulkar RS, McMahon LF, Saint S. Effects of work hour reduction on residents' lives. JAMA. 2005;294:1088-100.

Heitz RP, Unsworth N, Engle RW. Working memory capacity, attention control and fluid intelligence. In: Wilhelm O, Engle RW, editors. Handbook of Understanding and Measuring Intelligence.London: Sage Publications Inc; 2004.h.61-78.

HaywardRA. Estimating hospital deaths due to medical errors: preventability is in the eye of the reviewer. Jama - Am Med Assoc.2001.

Hendey GW, Barth BE, Soliz T. Overnight and postcall errors in medication orders. Acad Emerg Med. 2005 Jul; 12(7):629-34.

Iglehart JK. Revisiting duty-hour limits-IOM recommendations for patient safety and resident education. N Engl J Med. 2008;359:2633-5.

Katz ED, Sharp L, Ferguson E. Depression among emergency medicine residents over an academic year. Acad Emerg Med. 2006;13:284-7.

Kohn L, Corrigan J, Donaldson M. To err is human. Institute of Medicine; Washington, DC. 1999.

Lamberg L. Knitting up the raveled sleave of care: role of sleep and effect of its lack examined. JAMA.1996;354:1435-9.

Landrigan CP, Rothschild JM, Cronin JW. Effect of reducing interns' work hours on serious medical errors in intensive care units. N Engl J Med. 2004;351:1838-48

Morgenthaler T, Lee T, Alessi C, Friedman L, Nisha RA, Boehlecke B. Practice Parameters for the Clinical Evaluation and Treatment of Circadian Rhythm Sleep Disorders. Sleep. 2007:30;1445-59.

Undang - Undang no. 20 tahun 2013 tentang pendidikan Kedokteran.

West CP, Huschka MM, Novotny PJ, Sloan JA, Kolars JC, Habermann TM. Association of perceived medical errors with resident distress and empathy. JAMA 2006;296:1071-8.

WHO. World Health Organization (2010). World Health Statistic 2010. 